\title{
Polyporphyrin Complexes of Some Transition Metals Synthesis and Catalytic Properties
}

\section{A.V. SHAKHVOROSTOV ${ }^{1}$, Z. B. ATABEKOVA ${ }^{1 *}$, B.S. SELENOVA ${ }^{1}$, G.ZH. YELIGBAYEVA ${ }^{1}$ and G.I. DZHARDIMALIEVA ${ }^{2}$}

\author{
${ }^{1}$ Kazakh National Research Technical University named \\ after K.I. Satpayev, Almaty, 050000, Kazakhstan. \\ ${ }^{2}$ The Institute of Problems of Chemical Physics RAS, \\ Chernogolovka, Moscow Region, 142432, Russian Federation. \\ ${ }^{*}$ Corresponding author E-mail: zau888@ mail.ru \\ http://dx.doi.org/10.13005/ojc/320517
}

(Received: September 29, 2016; Accepted: October 15, 2016)

\begin{abstract}
The paper presents the results of synthesis of polyporphyrin structures and metal complex catalyzers at their basis. Porphyrin to be derived from the addition reaction of pyrrole and formaldehyde. Metal complex catalyzers to be derived at the reaction of complex formation of ions of $\mathrm{Mn}^{2+}, \mathrm{Co}^{2+}, \mathrm{Ni}^{2+}$ and $\mathrm{Fe}^{3+}$ with porphyrin. The structure, physical and chemical properties of derived materials to be examined with IR spectroscopy, differential thermal analysis, thermogravimetric analysis, scanning electron microscopy investigation. Catalytic activity of synthesized catalytic systems to be established at the reaction of decompounding of hydrogen peroxide and alkylaromatics oxidation by hydrogen peroxide. The processes have been conducted under soft conditions, and also at different organic solvents.
\end{abstract}

Keywords : Porphyrin, Metal complex catalyzers, Hydrogen peroxide, Oxidation, Alkylaromatics.

\section{INTRODUCTION}

Metal porphyrins are wide spread in Nature and are the part of the whole range of enzymes, which are the effective catalyzers of hydrocarbon oxidation reactions. The actual task is creation of industrially important oxidation processes for n-alkanes and aromatic hydrocarbons of catalytic systems on the basis of porphyrin compounds, operating under soft conditions ${ }^{1,2}$. Starting the late 70 s of XX century the vast number of porphyrin compounds have been synthesized and examined at oxidation reactions of different substrates ${ }^{3-8}$.

The main disadvantage of the systems is their relatively low stability, whereas during the reaction the porphyrin ligand itself is to decompose. For purposes of heterogenization of soluble metal 
porphyrins they can be immobilized at the surface of polymer or mineral carrying agent ${ }^{9-13}$. At papers ${ }^{14,15}$ for heterogenization of metal porphyrins a specific approach to be used, involving the polymerization of porphyrin fragments. Polymer metal porphyrin to be effectively catalyzed hexahydrobenzene oxidation by iodobenzene.

Therefore, synthetic metal porphyrin complexes are appeared to be high-selective catalyzers of oxidation functionalization of different classes of hydrocarbons. Thereat fixation of synthetic metal porphyrin complexes at the surface of polymer or mineral carrying agents may lead to derivation of stable catalyzers saving selectiveness and catalytic activity.

\section{MATERIALS AND METHODS}

The following materials were used for experimental studies:

\section{Reagents}

-Formaldehyde $\mathrm{CH}_{2} \mathrm{O}(99,5 \%)$ (Sigma-Aldrich); -Pyrrole $\mathrm{C}_{4} \mathrm{H}_{5} \mathrm{~N}(99,5 \%)$ (Sigma-Aldrich) was used without further purification;

- $\mathrm{HCl}$ hydrochloric acid (GOST 3118-77) as a catalyst, was used without further purification.

\section{Inorganic Salts}

-Manganese chloride $\mathrm{MnCl}_{2}$ * $4 \mathrm{H}_{2} \mathrm{O}$ brand "chemically pure" (JSC "Reahim");

-Ferrous sulphate $\mathrm{FeSO}_{4}{ }^{*} 7 \mathrm{H}_{2} \mathrm{O}$ brand "chemically pure" (JSC "Reahim");

-Cobalt nitrate $\mathrm{Co}\left(\mathrm{NO}_{3}\right)_{2}{ }^{*} 6 \mathrm{H}_{2} \mathrm{O}$ brand "chemically pure" (JSC "Reahim");

-Nickel nitrate $\mathrm{Ni}\left(\mathrm{NO}_{3}\right)_{2}{ }^{*} 6 \mathrm{H}_{2} \mathrm{O}$ brand "chemically pure" (JSC "Reahim").

All inorganic salts were further recrystallized from aqueous solutions.

\section{Alkylaromatic substrates}

-Cumene $\mathrm{S}_{9} \mathrm{~N}_{12}$ brand "chemically pure" (JSC "Reahim");

-Toluene $\mathrm{S}_{7} \mathrm{~N}_{8}$ brand "chemically pure" (JSC "Reahim");

•Ethylbenzene $\mathrm{S}_{8} \mathrm{~N}_{10}$ brand "chemically pure" (JSC "Reahim").

Alkylaromatic substances were further distilled under vacuum.

\section{Inorganic solvents}

-Bidistilled deionized water of $\mathrm{H}_{2} \mathrm{O}$ (BDV) (the resistance of 18 megohms).

Before using water the degassing process was carried out to remove dissolved air.

\section{Organic solvents}

-Dichloromethane $\mathrm{C}_{2} \mathrm{H}_{4} \mathrm{C}_{12}$ (DCM) (99,9\%) (Sigma Aldrich);

-Dimethyl $\mathrm{C}_{2} \mathrm{H}_{6} \mathrm{OS}$ (DMSO) $(99,9 \%$ ) (Sigma Aldrich);

-Dimethylformamide $\mathrm{C}_{3} \mathrm{H}_{7} \mathrm{NO}$ (DMF) $(99,9 \%)$ (Sigma Aldrich);

- $\mathrm{C}_{6} \mathrm{H}_{6}$ benzene brand "chemically pure" (JSC "Reahim") was further distilled under vacuum.

Original porphyrin $(P)$ is derived on classic methodology ${ }^{16}$, by the addition reaction of pyrrole and formaldehyde. At three-necked roundbottomed flask, equipped with back-flow condenser and offset for supply of inert gas, to a solution of 0.14 mole $(4.204 \mathrm{~g})$ of formaldehyde at $100 \mathrm{ml}$ of boiled bidistilled deionized water to be added $0.5 \mathrm{ml}$ $(0.595 \mathrm{~g})$ of hydrochloric acid $(37 \%)$. Further to be added 0.7 mole $(46.963 \mathrm{~g})$ of pyrrole conducted dropwise, maintaining an interval in time for previous drop fully stirred at the value. After the last portion of pyrrol to be added, the suspension to be brought to a boil on a heating plate and boiled within 40 minutes. After 40 minutes passed the heating to be terminated and the suspension had been left to

Table 1: Porphyrin synthesis conditions

\begin{tabular}{lcccccc}
\hline $\begin{array}{l}\text { M (pyrrole), } \\
\mathbf{g}\end{array}$ & $\begin{array}{c}\mathbf{M} \text { (formaldehyde), } \\
\mathbf{g}\end{array}$ & $\begin{array}{c}\mathbf{M}(\mathbf{H C L}), \\
\mathbf{g}\end{array}$ & $\begin{array}{c}\mathbf{T}, \\
{ }^{\circ} \mathbf{C}\end{array}$ & $\begin{array}{c}\tau, \\
\mathbf{h}\end{array}$ & $\begin{array}{c}\text { M(polyporphyrin), } \\
\mathbf{r}\end{array}$ & $\begin{array}{c}\text { Yield, } \\
\%\end{array}$ \\
\hline 46.963 & 4.204 & 0.595 & 100 & 1 & 9.246 & 68 \\
\hline
\end{tabular}


get cool in the open air down to room temperature. During the cooling process the brown crystals to be dropped out. Afterwards, the brown crystals to be filtered at Buchner funnel and left to dry under vacuum overnight. The experiment was conducted at the atmosphere of argon inert gas. After the reaction to be done, unwatered product represents the brown powder (the mass equals $11.829 \mathrm{~g}$ ). Afterwards the product additionally to be irrigated by some amount of hot solution of dichloromethane. After the extraction the pure porphyrin to be derived. The porphyrin synthesis scheme is shown in Figure 1.

At the table 1 are shown the data on polyporphyrin synthesis.

For polyporphyrin metal complexes synthesis (Me-PP) to a solution of 0.0016 mole of porphyrin at $100 \mathrm{ml}$ DMSO added with 0.008 mole of salt of metals Fe(III), $\mathrm{Co}(\mathrm{II}), \mathrm{Ni}$ (II) and $\mathrm{Mn}$ (II). The mixture was brought to reflux and maintained for 3 hours. After the time ran out DMSO to be evaporated under vacuum. Derived precipitation to be washed under hot water for dissolving of unreacted $\mathrm{MnCl}_{2}$. Filtered precipitation to be unwatered within 24 hours under vacuum at temperature $50^{\circ} \mathrm{C}$. The derived product does not dissolve at solvents common for mono-porphyrin derivatives. Obviously, during metal porphyrin complexes synthesis appears the formation of compound presenting oligomeric polymer chain consisting of porphyrin rings.

The process of formation of metal complexes appears by means of reaction of addition of divalent ion of metal to inner ring consisting of four pyrrole fragments (Figure 2). Continuous lines show metalorganic bonds, dashed lines show coordination interactions of nitrogen and metal atoms.
For the research of structure and physical properties of obtained materials the following physical and chemical methods were used.

\section{FT-IR spectroscopy (IR)}

IR spectra were recorded on a spectrophotometer Carry 660 Agilent (USA) at a temperature of $-25^{\circ} \mathrm{C}$. A sample weighing $5 \mathrm{mg}$ is placed in a mortar with $150 \mathrm{mg}$ of potassium bromide $(\mathrm{KBr})$ then milled until uniform in color and size of the mass of particles. The resulting mass is filled in a special pressing device between two polished metal plates that connect the vacuum pump, created a vacuum of 25 mbar. Special hydraulic press was pumped effort equal $\approx 9,5 \mathrm{~T}$. Maintained sample under pressure for $6 \sim 7$ minutes, then the resulting pellet was removed and placed in a special holder. The scanning speed was $1 \mathrm{~cm}^{-1} / \mathrm{sec}$, a scan range from 650 to $4000 \mathrm{~cm}^{-1}$. The number of background scans was 8 times, the test sample 24 times.

\section{Differential thermal analysis and termogravimetric analysis (DTA-TGA)}

Studies of thermal stability, and thermogravimetric measurement samples over a wide operating temperature range $\left(40^{\circ} \mathrm{C}\right.$ to $700^{\circ} \mathrm{C}$ ) were carried out on LabSys evo (France). Temperature set rate was $10^{\circ} \mathrm{C} / \mathrm{min}$, weight of sample $15 \sim 30 \mathrm{mg}$. The sample was placed in a cuvette of aluminum oxide $\left(\mathrm{Al}_{2} \mathrm{O}_{3}\right)$ with a tight lid and mounted between the thermocouple unit.

\section{X-ray diffraction (XRD)}

The crystal structure of the obtained metal complex catalysts Me-PP was investigated on the X-ray diffractometer X.Pert MPD PRO PANalytical (Holland) at a temperature $\mathrm{T}=25^{\circ} \mathrm{C}$, the mass of the sample ranged from $15-30 \mathrm{mg}$.
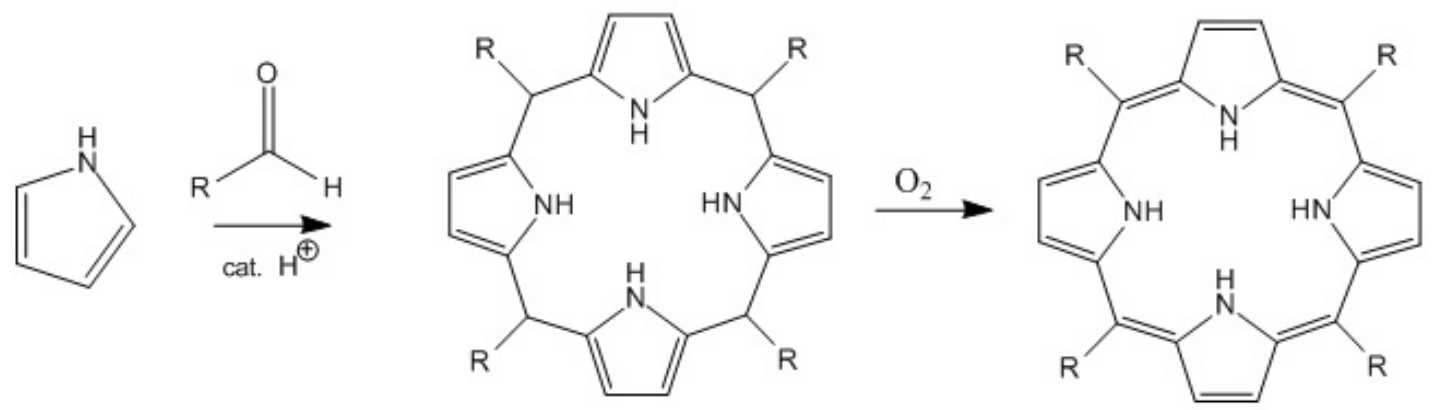

Fig. 1: Polyporphyrin synthesis scheme 


\section{Scanning electron microscopy (SEM)}

Particle size and surface structure of the particles were evaluated by using low vacuum scanning electron microscope JEOLJSM-6490LA (Japan). Voltage $15 \mathrm{kV}$ electron gun, a residual pressure of $60 \mathrm{~Pa}$.

\section{RESULTS AND DISCUSSION}

The structure and properties of derived metal porphyrin complexes to be examined by aforecited physical and chemical methods. The data on gravimetric measurements of derived metal complexes is shown at the table 2 .
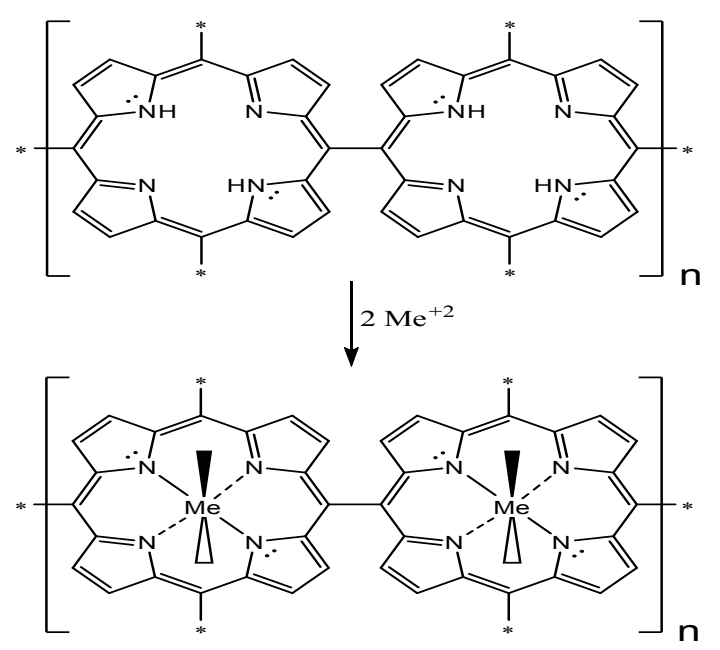

Fig. 2: Polyporphyrin metal complex structure formula

Table 2: Data on gravimetric measurements of porphyrin metal complex

\begin{tabular}{lcccc}
\hline $\begin{array}{l}\text { Metal } \\
\text { complex }\end{array}$ & $\begin{array}{c}\text { Mass, } \\
\mathbf{g}\end{array}$ & $\begin{array}{c}\delta, \\
\mathbf{g}^{*}\end{array}$ & $\begin{array}{c}\sigma, \\
\%^{* *}\end{array}$ & $\begin{array}{c}\omega, \\
\%^{* * *}\end{array}$ \\
\hline Mn-PP & 3.1018 & 0.1018 & 19.15 & 3.39 \\
Fe-PP & 3.2862 & 0.2862 & 53.00 & 9.54 \\
Co-PP & 3.2720 & 0.2720 & 47.87 & 9.06 \\
Ni-PP & 3.2993 & 0.2993 & 52.51 & 9.98
\end{tabular}

*-polyporphyrin mass change;

**- yield of reaction of complex formation compared to the theoretically possible one; $\omega$ - metal weight content at catalyzer.
Over the gained data the conclusion to be made that the reaction of complex formation in case of ions of $\mathrm{Mn}^{2+}$ goes weaker than with $\mathrm{Fe}^{2+}, \mathrm{Co}^{2+}$, $\mathrm{Ni}^{2+}$. This is due to the fact that for manganese (II) is less common to have complex formation, than for other d-elements. Obviously, in that case the formed complex compounds of manganese with pyrrole fragments are insufficiently stable, presence of which is limited by definite value of $\mathrm{pH}$ of solution.

The Figure 3 shows IR spectrum of original porphyrin (1) and Me-PP complexes (2-5). The wide absorption brand at $3392 \mathrm{~cm}^{-1}$ for porphyrin (1) corresponds the secondary and tertiary atoms of nitrogen, this wide peak persists at metal complexes (2-5) at absorption brands 385, 3389, 3371 and $3344 \mathrm{~cm}^{-1}$ respectively. Displacement of absorption peaks to the side of low-frequencies oscillations corresponds the nitrogen atoms conjugation with atoms of metal. The absorption brands within the range of $1635 \mathrm{~cm}^{-1}$ for porphyrin (1) and 1634, 1629, 1614, $1622 \mathrm{~cm}^{-1}$ for Mn-PP, Fe-PP, Co-PP, Ni-PP (2-5) corresponds to $\mathrm{C}=\mathrm{C}$ oscillations at pyrrole ring, and also subtle $\mathrm{C}=\mathrm{N}$ oscillations within the range of absorption at $\sim 1700 \mathrm{~cm}^{-1}$.

The Figure 4 shows thermogravimetric data of synthesized metal porphyrin complexes. The absence of phase transitions of the first and the

Table 3: Results of Alkyloramatic substrates oxidation reaction by hydrogen peroxide at metal porphyrin catalyzers at $70^{\circ} \mathrm{C}$

\begin{tabular}{lccc}
\hline Catalyzer Substrate & Oxidizer & $\begin{array}{c}\text { Conversion, } \\
\%\end{array}$ \\
\hline $\mathrm{Mn}-\mathrm{PP}$ & cumene & $\mathrm{H}_{2} \mathrm{O}_{2}$ & 28.6 \\
$\mathrm{Mn}-\mathrm{PP}$ & toluene & $\mathrm{H}_{2} \mathrm{O}_{2}$ & 17.7 \\
$\mathrm{Mn}-\mathrm{PP}$ & ethylbenzene & $\mathrm{H}_{2} \mathrm{O}_{2}$ & 43.4 \\
$\mathrm{Fe}-\mathrm{PP}$ & cumene & $\mathrm{H}_{2} \mathrm{O}_{2}$ & 33.3 \\
$\mathrm{Fe}-\mathrm{PP}$ & toluene & $\mathrm{H}_{2} \mathrm{O}_{2}$ & 20.4 \\
Fe-PP & ethylbenzene & $\mathrm{H}_{2} \mathrm{O}_{2}$ & 26.5 \\
Co-PP & cumene & $\mathrm{H}_{2} \mathrm{O}_{2}$ & 36.1 \\
Co-PP & toluene & $\mathrm{H}_{2} \mathrm{O}_{2}$ & 14.9 \\
Co-PP & ethylbenzene & $\mathrm{H}_{2} \mathrm{O}_{2}$ & 49.7 \\
Ni-PP & cumene & $\mathrm{H}_{2} \mathrm{O}_{2}$ & 21.2 \\
Ni-PP & toluene & $\mathrm{H}_{2} \mathrm{O}_{2}$ & 6.5 \\
Ni-PP & ethyl benzene & $\mathrm{H}_{2} \mathrm{O}_{2}$ & 16.8 \\
\hline
\end{tabular}


second type (absence of the peaks at the curves) within the interval of temperatures $50-150^{\circ} \mathrm{C}$, and also insignificant change of the mass of the samples shows the stability of metal porphyrin complexes. At further heating within 150 - 425 smooth change of mass to be presented to the side of decrease, obviously, it to be induced by gradual decomposition of metal complexes. At temperatures higher than 450 the destruction of Me-PP is about to happen.

Over the derived data X-ray phase diffraction analysis (Figure 5) the conclusion to be made that during the process of Me-PP metal complex formation the main structure to be represented as amorphous part.
The surface of synthesized metal porphyrins represents the grain structure with highly developed system of microscopic pores (Figure $6 a, b$ ).

Synthesized metal porphyrins as heterogenic catalyzers to be tested at the alkylaromatics oxidation reaction by hydrogen peroxide. The alkylaromatics oxidation reaction to be conducted at steel autoclave at atmospheric pressure. The process to be conducted at acetonitrile media. The hydrogen peroxide to be considered the preferable oxidizer at porous systems, as peroxide compounds are very mobile in the pores due to their smaller size. Therewith, the reagents are relatively cheap and environmentally safe. This system can be used

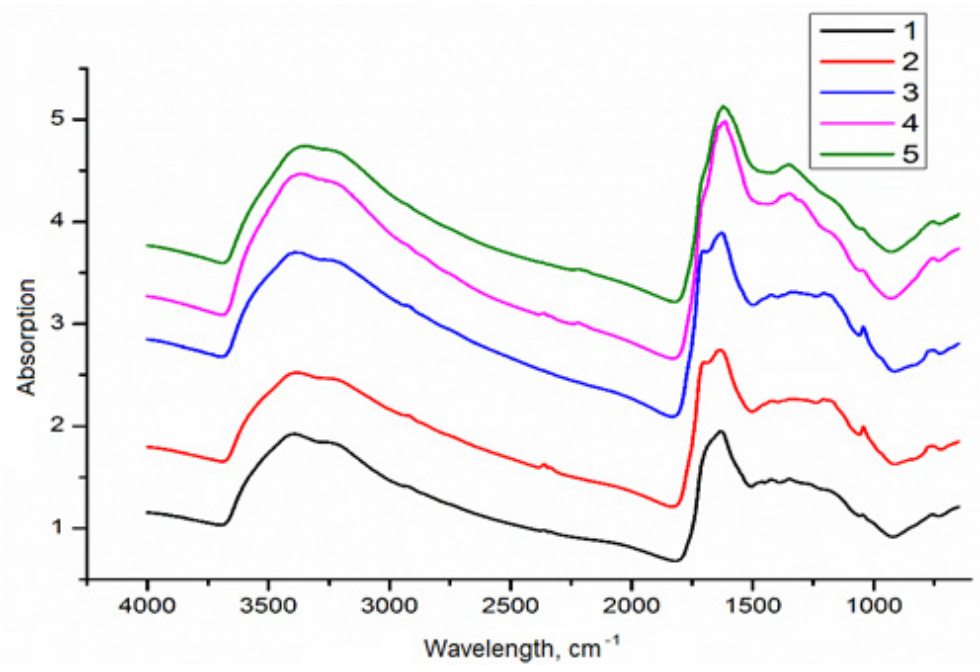

Fig. 3: IR spectra of porphyrin metal complex

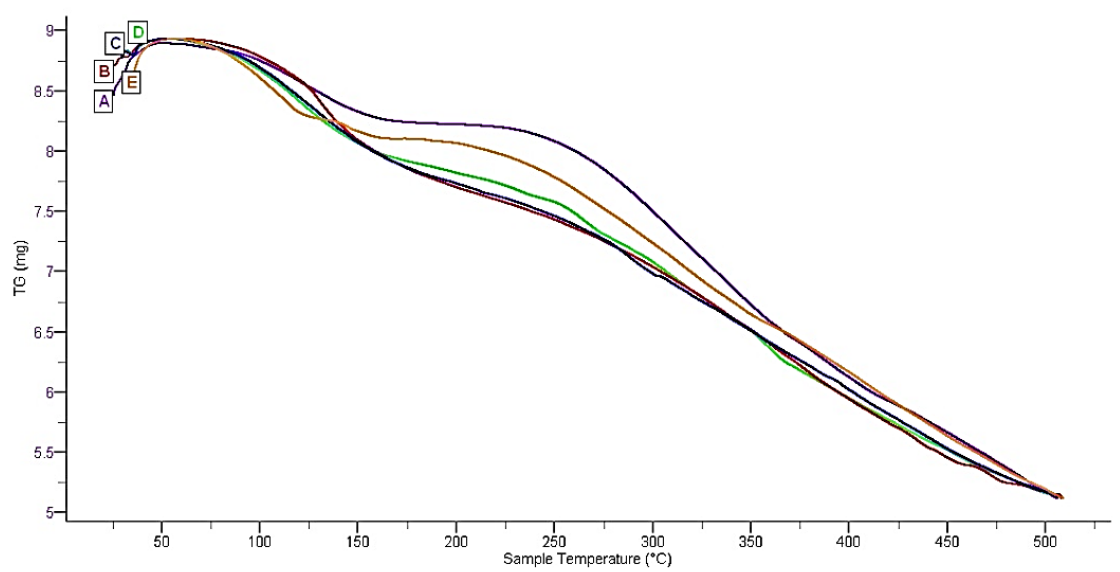

Fig. 4: TGA -DTA thermographs of porphyrin metal complex A - original porphyrin, B - Ni-PP, C - Co-PP, D - Fe-PP, E - Mn-PP 
in industrial and commercial scale. Nonetheless, aerobic oxidation, as expected, persists with lower speed because of inability of molecular oxygen to transfer into activated form comparing with highly active form, such as peroxides. Catalytic character of oxidation to be approved by the conduction of oxidation reaction in absence of any other catalyzer. As it turned out, the hydrogen peroxide is unable to oxidize the substrates in significant amount alone, it suggests that the reactions can persists only when the catalyzer presents at the system and facilitates the lowering activation energy of oxidation reaction.

The results of the experiments on cumene, toluene and ethylbenzene oxidation at metal complex catalyzers Mn-PP, Fe-PP, Co-PP, Ni-PP at the temperature $70^{\circ} \mathrm{C}$ are shown at the table 3 .

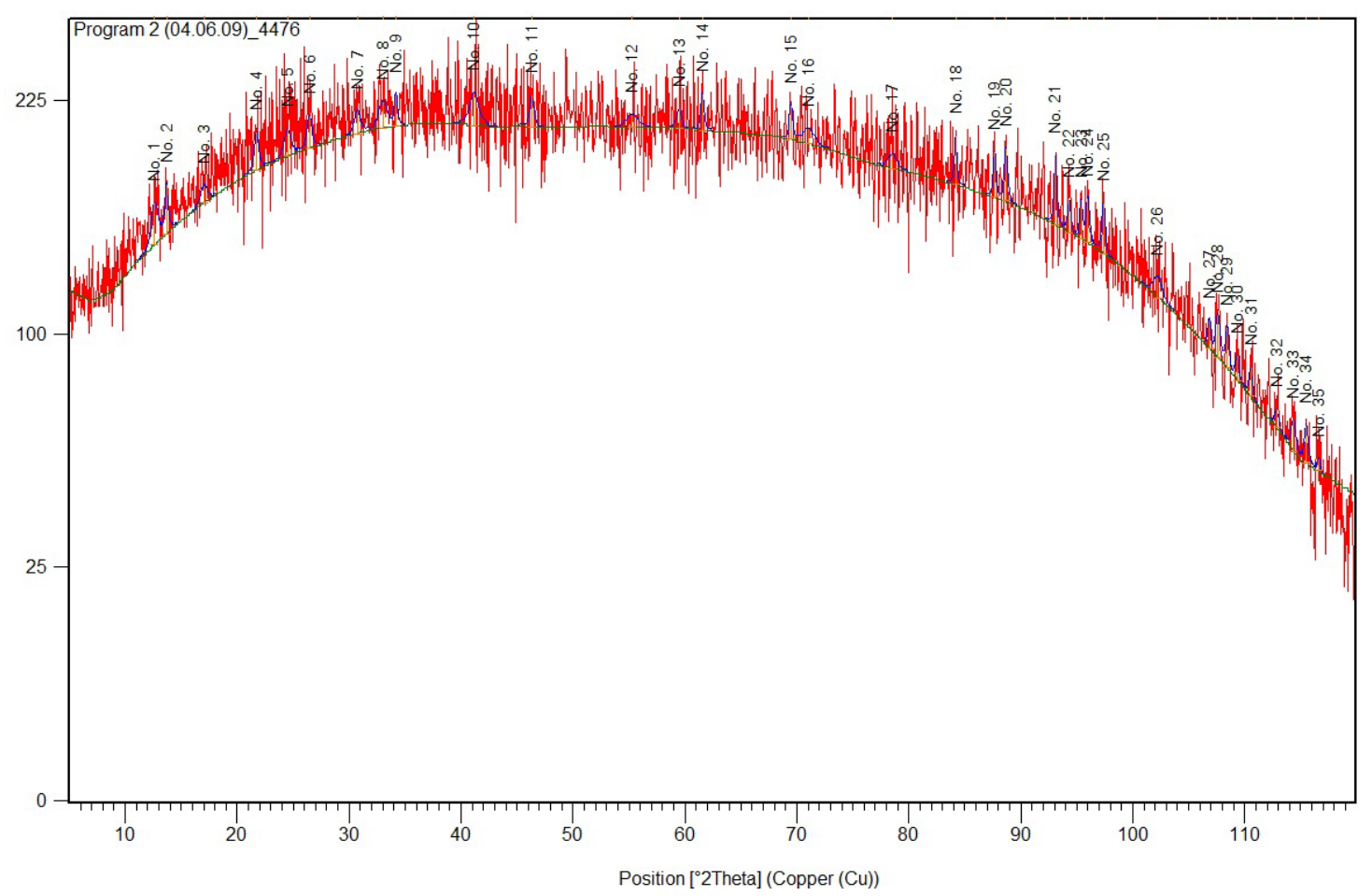

Fig. 5: X-ray phase spectrogram Co-PP
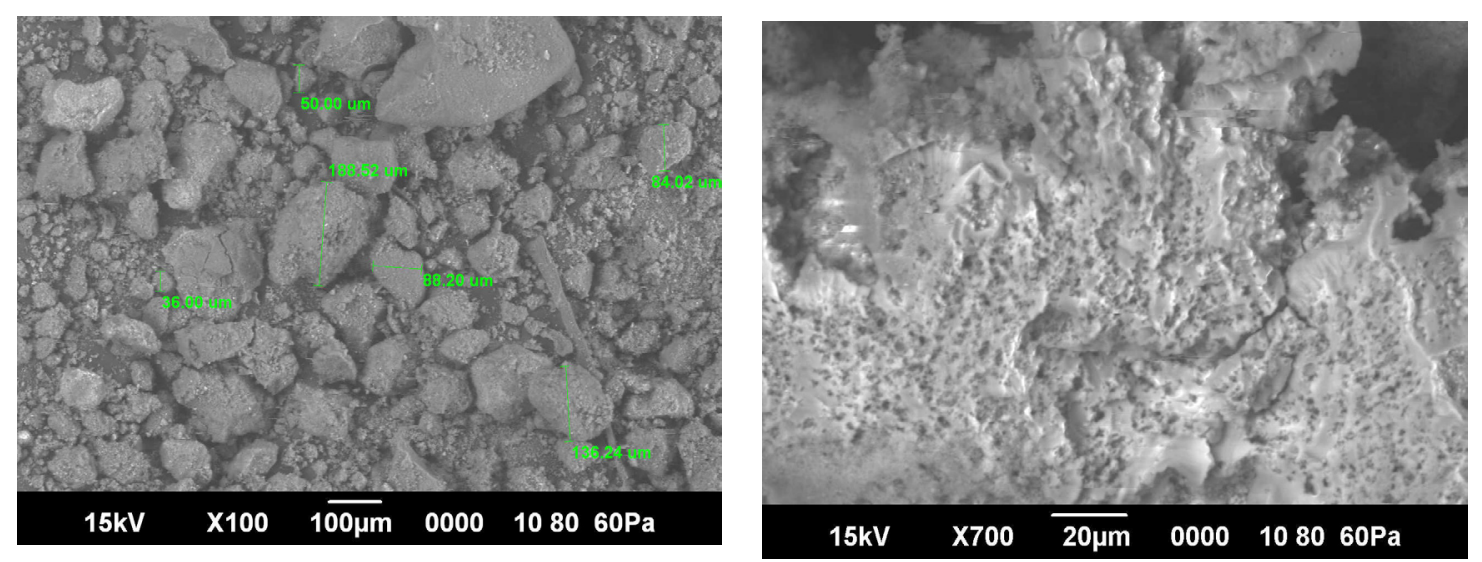

Fig. 6: SEM photographs of Me-PP metal complexes, geometric sizes and porosity 


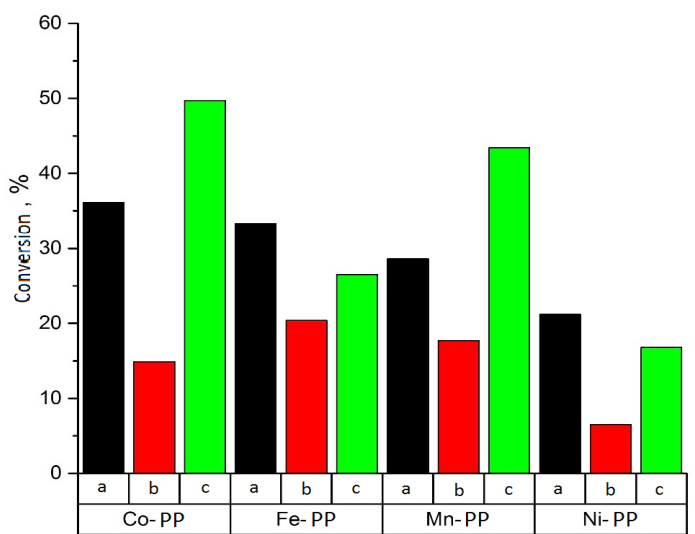

Fig. 7: Comparative activity of porphyrin metal complexes at oxidation of alkylaromatic hydrocarbons

Over gained results the diagram to be done for metal complex catalyzers activities - Figure 7. The most active at cumene oxidation is Me-PP, at toluene oxidation is Fe-PP, at ethyl benzene is $\mathrm{Mn}-\mathrm{PP}$. Thereat Ni-PP at all reactions is the least active.

During cumene oxidation metal complex catalyzers mainly form up the mixture consisting of phenol and acetone (1:1). During toluene oxidation manly forms up benzyl alcohol and a small amount of benzaldehyde and benzoic acid. In case of ethyl benzene there to be formed up the mixture of methyl phenyl carbinol and methyl phenyl ketone.

For stability examination of synthesized metal porphyrins at oxidation reaction for aromatic hydrocarbons by hydrogen peroxide there to be conducted series of experiments at the same sample of catalyzer charge. Consecutive experiments on ethyl benzene oxidation under the same conditions at $70^{\circ} \mathrm{C}$, at acetonitrile media, on catalyzer Me-PP are shown in Figure 8.

At the first cycle of reaction the conversion of ethyl benzene into oxygen-containing products to be $49,7 \%$. After the catalyzer to be derived from the reaction mass with further washed by water and

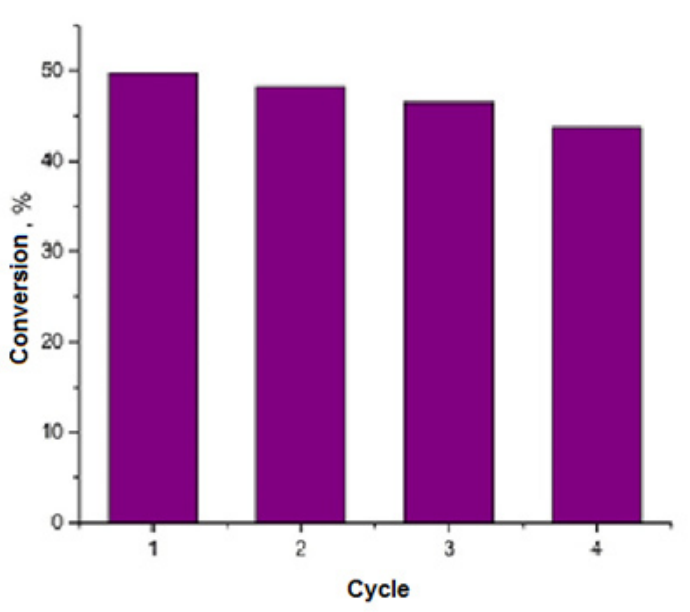

Fig. 8: Catalytic stability of Co-PP catalyzer

drying at vacuum oven it to be placed back to the reactor for conducting the second cycle, with fresh portion of organic substrate and oxidizer. Thereat, the substrate conversion for $1.5 \%$ has lowered. At the next cycles the gradual lowering of catalyzer activity to be observed. At the tenth cycle the catalyzer activity has lowered for $50 \%$ comparing the initial activity. This is obviously associated with gradual decomposition of polyporphyrin metal complex under impact of hydrogen peroxide.

\section{CONCLUSION}

Thus, on the basis of conducted examinations there has been developed the low temperature heterogenetic polyporphyrin metal complexes for oxidation of alkylaromatic hydrocarbons by hydrogen peroxide under the soft conditions. Data comparison over the catalytic activity of all examined catalyzers has shown that the favorable conditions for conducting the reaction of hydrogen peroxide decomposition at the atmospheric pressure are the temperature of $70^{\circ} \mathrm{C}$. The process of oxidation of cumene, toluene and ethyl benzene to be conducted under the temperature of $60-80$ by hydrogen peroxide at the acetonitrile media and other solvents. The most active catalyzer is Co-PP. 


\section{REFERENCES}

1. Matiyenko, L.I.; Mossolova, L.À.; Zaikov, G.Å. Chemical progress 2009 No. 3 (78) 228-247 (in Russian)

2. Punniyamurthy ,T.; Subbarayan, V.; Iqbal, J.; Chem. Rev. 2005.105, 6 ,2329-2364

3. Zipplies, M.F.; Lee, W.A.; Bruice, T.C. J. Am. Chem. Soc.1986 108, 15, 4433-4445

4. Battioni, P.; Renaud, J.P.; Bartoli, J.F.; ReinaArtiles, M.; Fort, M.; Mansuy, D. J. Am. Chem. Soc. 1988 , 110., 8462-8471

5. McLain, J.L.; Lee, J.; Groves, J.T. Biomimetic Oxidations Catalyzed Ed. B.L. Meunier: Imperial College Press 2000., 91

6. Zhang, X.B.; Guo, C.C.; Xu, J.B.; Yu, R.Q. Journal of Molecular Catalysis A: Chem. 2000, 154 31-38

7. Gherassimova, Î.À.; Shpakovskiy, D.B.; Milayeva, Å.R.; Loulowdi, Ì.; Hadjiliadas, Í. Moscow university Bulletin. Series 2. Chemistry 2007 48, 5. 322-328. (in Russian)

8. Esmelindro, M.C.; Oestreicher, E.G.; MárquezAlvarez, H.; Dariva, C.; Egues, S.M.S.;
Fernandes, C.; Bortoluzzi, A.J.; Drago, V.; Antunes, O.A.C. Journal of Inorganic Biochemistry 2005 .,99.2054-2061

9. Solovieva, A.B.; React. Polym. 1991 16, 1,918

10. Jun, K.W.; Shim, E.K.; Park, S.E.; Lee, K.W. Bull. Korean Chem. Soc. 1995 16, 5, 398407.

11. Rahiman Kalilur, A.; Bharathi Shanmuga, K.; Sreedaran, S.; Narayanan, V. Catal Lett. 2009 127., 175-180

12. Vianna Rosa, I.L.; Manso, C.M.C.P.; Serra, O.A.; lamamoto, Y. Journal of Molecular Catalysis A: Chemical 2000 ., 160 ,199-208

13. Shulpina, L.S.; Takaki, Ê.; Strelkova, Ò.V.; Shulpin, G.B. Oil chemistry 2008 48,.3., 220223. (in Russian)

14. Traylor, T.G. J.Am.Chem.Soc. 1991 113, 20 ,7821-7830

15. Wang, R.M.; Wang, Y.P. Chemistry Letters 1993, 5, 855

16. Alan, D. J. Am. Chem. Soc. 1966, 32,476 . 